\title{
Trypanosoma cruzi: Desferrioxamine decreases mortality and parasitemia in infected mice through a trypanostatic effect
}

Jerusa Marilda Arantes ${ }^{1,} 6^{*}$, Amanda Fortes Francisco ${ }^{2}$, Paula Melo de Abreu Vieira ${ }^{2}$, Maisa Silva, ${ }^{3}$ Márcio Sobreira Silva Araújo ${ }^{1}$, Andréa Teixeira de Carvalho', Maria Lúcia Pedrosa ${ }^{3}$, Cláudia Martins Carneiro', 4 , Washington Luiz Tafuri², Olindo Assis Martins-Filho', Silvana Maria Elói Santos. ${ }^{1,5}$

'Laboratório de Biomarcadores de Diagnóstico e Monitoração/ CpqRR/FIOCRUZ- Belo Horizonte, MG.

${ }^{2}$ Laboratorio de Imunopatologia - Núcleo de Pesquisas em Ciências Biológicas (NUPEB), Instituto de Ciências Exatas e Biológicas (ICEB), UFOP, MG, Brazil ${ }^{3}$ Departamento de Ciências Biológicas, ICEB, UFOP, MG, Brazil

${ }^{4}$ Departamento de Análises Clínicas, Escola de Farmácia, Universidade Federal de Ouro Preto

${ }^{5}$ Departamento de Propedêutica Complementar, Faculdade de Medicina/ UFMG- Belo Horizonte, MG.

${ }^{6}$ Pós- Graduação em Patologia/ Faculdade de Medicina/UFMG.

*Corresponding author: Silvana Maria Elói Santos, Departamento de Propedêutica Complementar, Faculdade de Medicina/ UFMG. Avenida Professor Alfredo Balena, 190 - Bairro Santa Efigênia - Belo Horizonte, 30130-100, Brazil, E-mail: eloisil@medicina.ufmg.br 


\begin{abstract}
Although DFA is known to reduce the intensity of $T$. cruzi mice infection, the mechanism underlying this effect is still unclear and may involve host and parasite factors. To investigate the impact of DFA on mice disease outcome, on $T$. cruzi biology and on host biomarkers, disease and parasitological studies were performed. DFA treated animals presented lower cumulative mortality rate in long term infection and lower parasitemia in both short and long term infection. DFA inhibited amastigotes and trypomastigotes growth in fibroblast culture, decreased parasite mobility, induced minor parasite apoptosis but did not change viability measured by trypan blue staining. No effect was observed in iron metabolism markers, erythrogram, leukogram, lymphocyte subsets, except for an increase in lymphocyte counts at $7^{\text {th }}$ d.p.i. The treatment in mice showed minor action on the cellular immune response of spleen. Beneficial DFA effects on mice $T$. cruzi infection may be due to trypanostatic effect, independently of interference on host iron metabolism and with minor effects on lymphocyte subpopulation counts.
\end{abstract}

Index Descriptors and Abbreviations: Trypanosoma cruzi (T.cruzi); Desferrioxamine (DFA), day post-infection (d.p.i), intraperitoneally (i.p.), notinfected with $T$. cruzi and not-treated with DFA (control); not-infected with $T$. cruzi and treated with DFA (control +DFA); infected with $T$. cruzi and not-treated with DFA ( $T$. cruzi); infected with $T$. cruzi and treated with DFA ( $T$. cruzi + DFA); serum iron binding capacity (TIBC), and Benznidazole (BZ). 


\section{Introduction}

Desferrioxamine (DFA) is a potent iron chelator used clinically to remove both intra and extracellular iron (Keberle, 1964; Zanninell et al., 1997; Hershko et al., 1998) and is known to modulate inflammation. It is an efficient antioxidant under normal conditions and oxidative stress, functioning via iron chelation, free radical scavenging and lipid chain breaking (Minotti et al., 1987; Rachidi et al., 1994).

This chelator is produced by the bacteria, Streptomyces pilosus (Keberle, 1964). It is a hexadentate hydroxamate that binds iron 1: 1 stoichiometric. DFA is hydrophilic and does not cross the cell membrane easily. It acts by chelating iron pools of the liver and the iron released by reticuloendothelial cells following hemoglobin breakdown (Fielding, 1965). The iron-bound complex, ferrioxamine, which has very high chemical stability, is excreted in urine or feces (White et al., 1988; Donfrancesco et al., 1996; Richardson, 1997). Mobilization of lowmolecular-weight iron by DFA is rapid. Removal of iron from tissues or cells by DFA is believed to first involve the mobilization of iron from ferritin and hemosiderin. DFA, however, is ineffective in mobilizing iron from transferrin and lactoferrin, and mobilizes iron from ferritin and hemosiderin very slowly, taking days to complete (Kontogiorghes, 1995; Richardson, 1997).

The utilization of chelators has been proposed as a strategy to interfere with the progression of a multitude of diseases such as cancer (Yu et al., 2006), infectious (Spellberg et al., 2005) and neurologic (Richardson, 2004) diseases, and atherosclerosis.

Many studies in vitro and in vivo have demonstrated that this chelator has been used in treatment of infection for protozoa. In protozoan diseases, iron chelator leads to growth inhibition effects in Plasmodium falciparum (Hershko and Peto, 1988) and in bloodstream forms of Trypanosoma brucei (Breidbach et al., 2002) being also considered a promising drug against Toxoplasma gondii using mice model (Mahmoud, 1999). Studies in human malaria showed that the treatment with DFA alone or in combination with standard therapy enhanced the parasite clearance in asymptomatic and severe malaria (Traore et al., 1991; Gordeuk et al., 1992; Mabeza et al., 1996). 
In experimental $T$. cruzi infection, the effect of iron chelation on disease evolution is dependent on parasite strain. Thus Pedrosa et al. (1990) demonstrated that, in comparison with a control group, mice infected with the YuYu strain developed a less severe form of the disease when treated on the 5th dpi with DFA at a dose of $10 \mathrm{mg} /$ mouse, whereas no differences were observed in animals infected with $\mathrm{Y}$ and $\mathrm{CL}$ strains. Arantes et al. (2007) showed that mice treated with DFA 14 days prior to infection with T. cruzi $Y$ strain and for 21 days after infection, presented lower levels of parasitaemia and reduced rates of mortality compared with infected but untreated animals. Furthermore, the infected groups exhibited lower levels of iron in the liver compared with non-infected animals of both treated and untreated groups. The serum iron levels of the infected but untreated group were, however, higher on the 21st dpi in comparison with the infected and treated group and the control group. More recently, the association of DFA and Benznidazole, the only etiological treatment commercially available for the disease, showed high efficacy and a mortality rate of $0 \%$ in mice (Francisco et al. 2008). All infected groups presented lower levels of iron in the liver, and the serum iron concentrations were greater in the groups treated with DFA and the association DFA/Benznidazole compared to the infected group.

Although clear evidence that DFA is able to reduce the intensity of infection by $T$. cruzi in mice, the mechanism of this effect is still unclear and may involve different mechanisms. Thus, the objective of this study was to demonstrate the impact of DFA in mice disease outcome, on T. cruzi biological and on host biomarkers. 


\section{Materials and methods}

Ethical issue: This research was reviewed and approved by in advance by the institutional Animal Care and Use Committee (CETEA 153/07).

\section{Impact of DFA in mice disease outcome}

\section{Parasitemia and mortality in long term infection}

Swiss mice were treated with DFA $5 \mathrm{mg}(\mathrm{n}=10)$ or sterile water $(n=10)$ daily by intraperitoneal (ip) route $(0.05 \mathrm{ml})$ during 14 days before infection with 500 blood forms of $Y$ strain T. cruzi and continuing up to 14 d.p.i. Parasitemia was checked and counted daily according to Brener (1962) methodology starting at fourth day after inoculation. Mortality was also observed daily.

\section{Impact of DFA on $T$. cruzi biological parameters}

\section{T. cruzi growth inhibition assay}

Parasites and culture procedures: T. cruzi (Tulahuen strain) expressing the Escherichia coli beta-galactosidase gene were grown on monolayer of mouse L929 fibroblasts. Cultures to be assayed for beta-galactosidase activity were grown in RPMI 1640 medium (pH 7.2-7.4) without phenol red (Gibco BRL) plus $10 \%$ fetal bovine serum and $2 \mathrm{mM}$ glutamine.

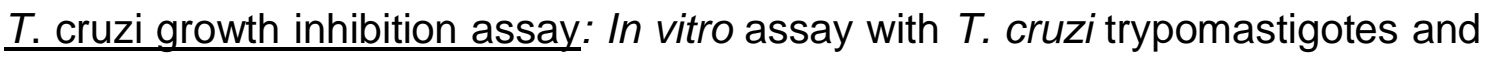
amastigote intracellular forms was performed according protocols established by Buckner et al. (1996) with modifications. Ninety-six-well tissue culture plates were seeded with L929 fibroblasts at $4.0 \times 10^{3}$ per well in $80 \mu \mathrm{l}$ and incubated overnight. Beta-galactosidase- expressing trypomastigotes were then added at $4.0 \times 10^{4}$ per well in $20 \mu \mathrm{l}$. After $2 \mathrm{~h}$, the medium with trypomastigotes that not penetrated in cells was discarded and replaced by $200 \mu \mathrm{l}$ of fresh medium. After $48 \mathrm{~h}$, the medium was discarded again and replaced by $180 \mu \mathrm{l}$ of fresh medium and test compounds in $20 \mu \mathrm{l}$. The compound DFA - (Desferal $\AA$, Novartis) was tested in triplicate in different concentrations $(100,50,20,10,5$ and $1 \mu \mathrm{g} / \mathrm{mL})$. After 7 days of incubation, chlorophenol red beta-D-galactopyranoside (CPRG) 
(100 $\mu \mathrm{M}$ final concentration) and Nonidet P-40 ( $0.1 \%$ final concentration) were added to the plates and incubated overnight at $37^{\circ} \mathrm{C}$ and the absorbance measured at $570 \mathrm{~nm}$ in an automated micro plate reader. Benznidazole (BZ) at its $\mathrm{IC}_{50}(1 \mu \mathrm{g} / \mathrm{ml}=3.81 \mu \mathrm{M})$ was used as positive control. The results are expressed as percentage of trypanocidal activity (Oliveira et al., 2006).

\section{Mobility, viability (membrane integrity) and apoptosis assays}

\section{Trypomastigotes of $\mathrm{Y}$ strain $T$. cruzi culture}

L929 cells were maintained in our laboratory by serial passages and kept frozen in liquid nitrogen. For the assays, $1 \times 10^{6}$ L929 cells were seeded in tissue culture flasks (Falcon $75 \mathrm{~cm}^{2}$ ) with $10 \mathrm{ml}$ of DMEM medium (GIBCO, Grand Island, New York, USA) containing $10 \%$ FBS, and incubated at $37{ }^{\circ} \mathrm{C}$ in a humidified air containing $5 \% \mathrm{CO}$. After 2 or 3 days, the monolayer was infected with $5 \times 10^{6}$ trypomastigotes of $T$. cruzi-Y strain obtained from experimentally infected mice (Brener \& Chiari, 1963). Cultures were maintained in DMEM, $10 \%$ of $\mathrm{FBS}$ at $33{ }^{\circ} \mathrm{C}$ in $5 \%$ of $\mathrm{CO} 2$ at $95 \%$ humidity (Bertelli et al., 1977). After 5- 6 days the trypomastigotes were harvested from the supernatant. Cell debris and amastigotes were removed by differential centrifugation at $100 \times \mathrm{g}$ for $10 \mathrm{~min}$ at room temperature. Supernatant containing most of the parasites were centrifuged at $1000 \times \mathrm{g}$ for $15 \mathrm{~min}$ at $4{ }^{\circ} \mathrm{C}$. Pellet was washed three times in $0.15 \mathrm{M}$ phosphate buffered saline, $\mathrm{pH} 7.2$ (PBS) supplemented with 10\% FBS. Cultures were performed under different conditions depending on specific assays.

\section{Mobility assay}

Trypomastigotes of $T$. cruzi $-Y$ strain were cultured in the presence of different concentrations of DFA $(1,5,10,20,10,50$ and $100 \mu \mathrm{g} / \mathrm{mL})$, gentian violet (50 $\mu \mathrm{g} / \mathrm{mL})$ or $B Z(1 \mu \mathrm{g} / \mathrm{mL})$ for $1,3,6,9$ or 12 hours).

For the determination of trypomastigote mobility, $10 \mu \mathrm{L}$ from suspension of $10 \mathrm{x}$ $10^{6}$ parasites was applied to Neubauer chamber and the percentage of mobile parasites was calculated under light microscopy. 


\section{Trypan blue staining}

Trypomastigotes of $T$. cruzi $-Y$ strain were cultured in the presence of different concentrations of DFA $(1,5,10,20,10,50$ and $100 \mu \mathrm{g} / \mathrm{mL})$, gentian violet (50 $\mu \mathrm{g} / \mathrm{mL}), \mathrm{BZ}$ (1 and $5 \mu \mathrm{g} / \mathrm{mL})$ or DFA (1, 5 and $10 \mu \mathrm{g} / \mathrm{mL})+\mathrm{BZ}(1 \mu \mathrm{g} / \mathrm{mL})$, for 0.5 , $1,3,6,9$ or 12 hours).

For the determination of viability of trypomastigotes, $1 \times 10^{5}$ parasites were resuspended in PBS, $1 \mu \mathrm{L}$ of trypan blue $0.4 \%$ and incubated for 10 minutes at room temperature before analysis by flow cytometry. A total of 10000 events were acquired and analysed using Flow-Jo software. The percentage of viable parasites (no staining by Trypan blue) was defined by histogram of trypan blue content ( $x$-axis, trypan blue fluorescence) versus counts ( $y$-axis).

\section{Annexin and PI staining}

Trypomastigotes of $T$. cruzi $-Y$ strain were cultured in the presence of different concentrations of DFA $(1,5,10,20,10,50$ and $100 \mu \mathrm{g} / \mathrm{mL}$ ), gentian violet (50 $\mu \mathrm{g} / \mathrm{mL}), \mathrm{BZ}$ (1 and $5 \mu \mathrm{g} / \mathrm{mL})$ or DFA (1, 5 and $10 \mu \mathrm{g} / \mathrm{mL})+\mathrm{BZ}(1 \mu \mathrm{g} / \mathrm{mL})$, for 0.5 , 1 or 3 hours).

For this experiment, $1 \times 10^{6}$ parasites were resuspended in a $\mathrm{Ca}^{2+}$-enriched binding buffer (Apoptosis Detection Kit, Sigma, USA). Suspension of parasites were double stained with FITC-conjugated annexin $\mathrm{V}$ and $\mathrm{PI}$ for $10 \mathrm{~min}$ at room temperature and protected from light. They were immediately analyzed on flow cytometer in their staining solution. Annexin $\mathrm{V}$ and $\mathrm{PI}$ emissions were detected in FL-1 (band pass 530nm, band width $30 \mathrm{~nm}$ ) and FL-2 (band pass $585 \mathrm{~nm}$, band width $42 \mathrm{~nm}$ ) channels, respectively. Parasites showing no staining by either propidium iodide or annexin V-FITC was considered alive. Parasites stained with the annexin V-FITC alone were considered in early apoptotic process. Parasites stained by both propidium iodide and annexin V-FITC were considered dead.

\section{Parasitemia by short term infection}

Swiss male mice $(n=20)$ were inoculated with 50.000 blood forms of $Y$ strain $T$. cruzi. At parasitemia peak (seven days after infection), animals were divided into 4 groups $(n=5)$ and treated with DFA, BZ or both, as outline below: 
Group 1: Controls (no treatment)

Group 2: Treated with DFA - 25 mg / kg

Group 3: Treated with BZ - 500 mg / kg

Group 4: Treated with BZ (500 mg / kg) and DFA (25 mg / kg)

The number of circulating parasites was determined at the beginning of the experiment according to Brener (1962) and considered as a $100 \%$ match of parasitemia (time 0). Parasitemia was determined 3 and 6 hours after infection and drug administration and compared with time 0 to calculate the reduction percentage in circulating blood trypomastigotes number (Brener et al., 1984).

\section{Impact of DFA on host biomarkers}

\section{Biochemical, hematological and immunological analysis of DFA treated mice}

Thirty-day old swiss mice $(n=30)$ were treated with daily ip DFA $5 \mathrm{mg}$ from 14 days before infection with 500 blood forms of $Y T$. cruzi and continuing to 7,14 or 21 after infection. Control animals $(n=30)$ received sterile water.

Fifteen animals of each group were infected by ip injection of 500 bloodstream forms of the Y T. cruzi strain (Filardi \& Brenner, 1984).

Animals were divided in four experimental groups $(n=15)$ : not-infected and nottreated (control); not-infected and treated (control +DFA); infected and not-treated (T. cruzi); infected and treated (T. cruzi + DFA).

Animals were evaluated on the day of inoculum (0), $7^{\text {th }}, 14^{\text {th }}$ and $21^{\text {st }}$ d.p.i.

Biochemical analysis of iron metabolism (ferritin, serum iron, total ironbinding capacity)

Serum ferritin was determined by ELISA assay (Immunoperoxidase assay for determination of ferritin in mouse sera Kit \#E-90F, Immunology Consultants Laboratory, Newberg, USA). Serum iron was determined in nonhemolyzed serum samples by spectrophotometric analysis using commercially available kit (Ferrozine \#38 Labtest, Lagoa Santa, Brazil) and employing an iron standard of $89.5 \mu \mathrm{mol} / \mathrm{L}$. The iron binding capacity was determined in nonhemolyzed serum 
samples by spectrophotometric analysis using commercially available kit (Ferrozine \#41 Labtest, Lagoa Santa, Brazil), and employing an iron standard of $170 \mu \mathrm{mol} / \mathrm{L}$. Total iron-binding capacity (TIBC) was calculated by serum iron + CLLF ( latent capacity of iron binding).

\section{Mouse blood cell counts}

The blood cell counts were determined using an electronic hematology particle counter from ABC Vet (Horiba, ABX Diagnostics). Differential leukocyte count was performed by Giemsa stained blood smears and a total of 100 cells were counted. Blood was collected by orbital plexus puncture.

\section{Flow cytometry immunophenotyping of cultured spleen cells}

Three animals from each group were sacrificed at different times of infection: day of inoculum Animals were evaluated on the day of inoculum (0), $7^{\text {th }}, 14^{\text {th }}$ and $21^{\text {st }}$ d.p.i.

\section{Spleen cell suspension}

The suspensions of spleen cells were prepared in accordance to Taylor et al., 1987. The organ was immersed in cold RPMI 1640 (5 mL) in Petri dish and placed on ice for maceration. Fragments were pressed using blunt glass rod and then filtered on stainless steel gaze to obtain single cell suspension. The cell suspension was washed twice in RPMI-1640 and resuspended at a concentration of $1 \times 10^{7}$ cells $/ \mathrm{mL}$.

In vitro short-term culture of spleen cells

Suspensions of spleen cells were incubated in the presence of $1 \mathrm{~mL}$ of RPMI1640 (GIBCO, Grand Island, NY, USA) in polypropylene tubes (Falcon, BD Pharmingen) for $12 \mathrm{~h}$ at $37^{\circ} \mathrm{C}$ in a $5 \% \mathrm{CO} 2$ humidified incubator followed by incubation with Brefeldin A (BFA) (Sigma, St Louis, MO, USA), at a final concentration of $10 \mu \mathrm{g} / \mathrm{ml}$ for an additional period of $4 \mathrm{~h}$.

Immunostaining for cell surface markers

At the end of incubation period, cells were treated with EDTA (Sigma) at a final concentration of $20 \mathrm{mM}$ for $10 \mathrm{~min}$, at room temperature and washed once with FACS buffer (PBS $0.5 \%$ of bovine serum albumin, BSA; Sigma, $\mathrm{pH} 7.4$ ), by centrifugation at $600 \mathrm{~g}$ for $7 \mathrm{~min}$ at room temperature, and resuspended to half 
original volume with FACS buffer. Samples of $400 \mu \mathrm{L}$ of cell suspension from cultures were dispensed into 5 -ml polystyrene tubes (Falcon), each containing 3 $\mu \mathrm{L}$ of anti-mouse CD4, anti- mouse CD8 and anti- mouse CD19 (Caltag laboratories) or $3 \mu \mathrm{L}$ of anti- mouse CD49 (BD Pharmingem) labeled with FITC. After incubation for $30 \mathrm{~min}$ at room temperature in the dark, cell surface-stained samples were treated with $2 \mathrm{ml}$ of FACS Lysing/fix Solution (BD Pharmingen), immediately vortexed and re-incubated for an additional period of 3 min. After this period, the suspension was centrifuged at $400 \mathrm{~g}$ for 10 minutes at room temperature, and the supernatant was removed. The cells were washed twice with $2 \mathrm{~mL}$ PBS (phosphate buffered saline $0.15 \mathrm{M}, \mathrm{pH}$ 7.2) and then fixed with $100 \mu \mathrm{L}$ of FACS FIX solution (10.0 g/l paraformaldehyde, $10.2 \mathrm{~g} / \mathrm{l}$ sodium cacodylate and $6.65 \mathrm{~g} / \mathrm{l}$ sodium chloride).

Flow cytometry acquisition and analysis

Flow cytometry acquisition was performed using a FACScalibur flow cytometer (BD Pharmingen) considering a total of 30,000 events per tube. CELL QUEST software (Becton, Dickinson San Jose, CA, USA) provided by the manufacturer was used for data acquisition and analysis.

\section{Statistical analysis}

Statistical analyses of the data were carried out using GraphPad Prisma software (GraphPad Software 5.0, San Diego, CA, USA). Data were initially assessed by one-way analysis of variance (ANOVA) between days: when interactions were significant, the Tukey test was used to determine the specific differences between mean values. The results of differences between groups were statistically evaluated using unpaired Students $t$-test. Values are expressed as means \pm standard deviation: differences in mean values were considered significant at the $p<0.05$ level. 


\section{Results}

\section{Impact of DFA in mice disease outcome}

Considering the complex network triggered during $T$. cruzi infection, several factors including those related to the parasite and those inherent to host immune response could be associated with different disease outcome observed following DFA treatment.

To further focus this phenomenon, we have investigated parasite and host parameters aiming to identify mechanisms underlying the DFA impact in the course of $T$. cruzi infection.

\subsection{DFA reduces parasitemia and mortality in $Y$ strain T.cruzi infected mice}

Animals were treated with DFA $5 \mathrm{mg}$ or sterile water daily by intraperitoneal (ip) route $(0.05 \mathrm{ml})$ during 14 days before infection with 500 blood forms of $Y$ strain T. cruzi and continuing up to 14 d.p.i

At 14 days post infection, a decrease in parasitemia and in mortality was seen in DFA treated mice $(p<0.05)$ (Figure 1a). The average parasitemia value in DFA group mice (46,444 trypomastigotes/ $0.1 \mathrm{ml}$ of blood) was 5.4 times lower than in control group $(250,444$ trypomastigotes $/ 0.1 \mathrm{ml}$ of blood) $(p<0.05)$.

It was observed that $67 \%$ of the animals in the control group died, whilst the death rate in the DFA group was $33 \%(p<0.05)$.

\section{Impact of DFA on T. cruzi biological parameters}

2.1 DFA decreases parasite growth in in vitro fibroblast culture and mobility of trypomastigotes in culture

Using fibroblast culture, we evaluated $Y$ strain $T$. cruzi growth in the presence of DFA. The activity of the DFA, shown grown inhibition of amastigotes and trypomastigotes, is presented in Figure 1b. Using here benzonidazol as a drug control, the chelator was shown to be active in a dose of $100 \mu \mathrm{g} / \mathrm{mL}$ (IC $\left.{ }_{50}\right)$. In 
this concentration of DFA, the percentage of reduction of parasites was $49 \%$, whereas treatment with $\mathrm{BZ}(1 \mu \mathrm{g} / \mathrm{mL})$ was reduced in $93 \%$.

Since DFA was not very active in decreasing in vitro parasite growth, we decided to investigate a putative trypanostatic action. To test the effect of DFA on parasite motility, we counted the number of mobile trypanosome in the supernatant of L929 cells, using different concentrations of DFA (1, 5, 10, 20, 50 and $100 \mu \mathrm{g} / \mathrm{mL}$ ) and times of incubation (1, 3, 6, 9 and 12 hours) (Figure 1c). After 1 hour incubation, no difference was seen among all groups.

After 3 hours of incubation, DFA in concentrations higher than $10 \mu \mathrm{g} / \mathrm{mL}$ showed more efficiency than BZ $1 \mu \mathrm{g} / \mathrm{mL}$ in reducing parasite motility $(p<0.05)$. After 6 hours incubation, this difference was not observed. Gentian violet was used as positive control.

\subsection{DFA does not alter membrane integrity and induces minor apoptosis}

Membrane integrity was analyzed by trypan blue staining.

Infected L929 cells were cultured in the presence of different concentrations of DFA $(1,5,10,20,50$ and $100 \mu \mathrm{g} / \mathrm{mL})$ or BZ (1 and $5 \mu \mathrm{g} / \mathrm{mL})$ and times of incubation $(0,0.5,1,3,6,9$ and 12 hours). Trypomastigotes from supernatant were stained with trypan blue. $70-90 \%$ of parasites remained viable in all tested concentrations of DFA or BZ, with no difference between groups (Table 1).

Apoptosis induced by DFA was assessed by phosphatidylserine externalization. Similarly to the results of viability by flow cytometry, the majority the tripanosomes treated with DFA showed no staining by either propidium iodide or annexin V-FITC up to 3 hours of incubation (Figure 2), suggesting parasite preservation. As propidium iodide is a membrane-permeable nuclear stain, these results also point toward membrane integrity. In the other side, all dead parasites treated with DFA showed phosphatidylserine externalization.

\subsection{DFA reduces parasitemia in in vivo short time test}

Animals were infected with 50.000 parasites and treated with DFA (25 mg/kg) and/or BZ (500mg/kg) (Figure 3). Parasitemia, 3 hours after infection, was 
significantly reduced in DFA (65.11\%), BZ (65\%) and DFA + BZ (89.9\%) treated mice. Nevertheless, 6 hours after infection, only BZ or DFA + BZ treated animals persisted with lower parasitaemia.

\section{Impact of DFA on host biomarkers}

\subsection{DFA does not affect host iron metabolism}

To investigate if the effect of DFA on disease progression was due to host iron metabolism impairment, we analyzed ferritin, serum iron and total iron-binding capacity (TIBC) levels in infected and DFA treated animals. Unexpectedly, these parameters did not differ between groups (Figure 4), suggesting that DFA effect on parasite was not dependent on host iron metabolism.

\subsection{DFA does not alters mouse blood cell counts and lymphocytes subpopulation}

The effect of DFA in blood cells was also investigated. The results of mouse blood cell counts are presented in tables $\mathbf{2}$ and $\mathbf{3}$.

No difference on erythrogram (erythrocytes, hemoglobin, hematocrit) and platelet counting was seen.

The results of differential leukocytes counts showed that $T$. cruzi + DFA animals showed higher percentage of lymphocytes compared to $T$. cruzi group in $7^{\text {th }}$ d.p.i.

To further characterize the effect of DFA in lymphocyte subpopulation, we performed immunophenotypical analysis of spleen cells.

In figures $\mathbf{5}$ and $\mathbf{6}$, phenotypic profiles of splenic lymphocytes populations from different experimental groups were presented. NK cells (CD49+), T lymphocytes $\left(\mathrm{CD} 4^{+}+\mathrm{CD} 8^{+}\right)$, B cells $\left(\mathrm{CD} 19^{+}\right)$and $\mathrm{T}$ cell subpopulations $\left(\mathrm{CD} 4^{+}\right.$and $\left.\mathrm{CD} 8^{+}\right)$ were analyzed.

No difference was seen between groups, although longitudinal differences were noted inside each group. In the control group, a decreased in populations of $B$ cells at $21^{\text {st }}$ d.p.i compared to $7^{\text {th }}$ d.p.i. was observed. In control + DFA group, an increased in NK cells populations was observed at $14^{\text {th }}$ and $21^{\text {st }}$ d.p.i in comparison to $7^{\text {th }}$ d.p.i. T cells populations showed an increased at $21^{\text {st }}$ d.p.i compared to day 0 and $7^{\text {th }}$ d.p.i. In $\mathrm{CD} 8^{+} \mathrm{T}$ cells populations an increased at $14^{\text {th }}$ and $21^{\text {st }}$ d.p.i in relation to the $7^{\text {th }}$ d.p.i. was observed. However, for the 
populations of $B$ cells a decreased was observed at 21 st d.p.i compared to $7^{\text {th }}$ d.p.i.

In $T$. cruzi group, an increased in NK cells population was observed at $7^{\text {th }}$ and $21^{\text {st }}$ d.p.i compared to day 0 . The populations of $T$ cells showed an increased at $21^{\text {st }}$ d.p.i compared to $14^{\text {th }}$ d.p.i and day 0 . In populations of CD4 ${ }^{+} T$ cells was observed an increased at $21^{\text {st }}$ d.p.i in relation to the $7^{\text {th }}$ d.p.i. It was observed in populations of $\mathrm{CD}^{+} \mathrm{T}$ cells an increased in the $21^{\text {st }}$ d.p.i compared to $14^{\text {th }}$ d.p.i and day 0 and a decreased in the $14^{\text {th }}$ d.p.i compared to day 0 . However, for the populations of $B$ cells was observed a decreased in the 21st d.p.i compared to $14^{\text {th }}$ d.p.i and day 0 .

In the T. cruzi + DFA group was observed an increased in the populations of $T$ cells in the $21^{\text {st }}$ d.p.i in compared to $7^{\text {th }}$ d.p.i and day 0 . In populations of CD8 ${ }^{+} T$ cells was observed an increased in the 21 st d.p.i in relation to the $7^{\text {th }}$ d.p.i and a decreased in the $7^{\text {th }}$ d.p.i compared to day 0 . However, for the populations of $B$ cells was observed a decreased in the 21 st d.p.i compared to $7^{\text {th }}$ d.p.i. 


\section{Discussion}

Although clear evidence that DFA is able to reduce the intensity of infection by $T$. cruzi in mice, the mechanism of this effect is still unclear and may involve host and parasite factors.

In this paper, parasitemia and mortality data demonstrate that the intensity of mice infection by $Y$ strain was attenuated by DFA treatment. These results are in agreement with our previous study that demonstrated reduced parasitemia and mortality in mice treated with DFA and infected with $\mathrm{Y}$ strain of T.cruzi (Arantes et al., 2007; Francisco et al., 2008).

In evaluating of impact of DFA on T. cruzi biological parameters, this is the first study that shows the activity of DFA $(100 \mu \mathrm{g} / \mathrm{mL})$ directly on $T$. cruzi forms, indicating that DFA can have other mechanisms of action besides iron depletion.

Since DFA was not very active in decreasing in vitro parasite growth, we decided to investigate the capacity of DFA in damaging membrane integrity of trypomastigotes. We found that DFA does not induce parasite death. So we searched a putative trypanostatic action. A decrease in motility was observed when trypomastigotes were culture in the presence of DFA. This result is of great importance. Little is known about DFA activity on $T$. cruzi and this decrease can come to be a major step in the mechanism of action of DFA on parasite in vitro. DFA initially can lead to static effect on the parasite in culture and we came assume that the initial contact with parasite, others mechanisms of action may be involved. Effects on motility are observed in parasites with the use of certain drugs. Grimm et al., 2001, demonstrated effect leishmaniostatic in flow cytometry analysis.

It is the first paper that shows a possible involvement of apoptosis as possibly mechanism of DFA action in Trypanosoma cruzi. In this work, T. cruzi induces minor apoptosis with the utilization of DFA and others works should be conducted to demonstrate this possible mechanism in this parasite.

Flow cytometry has become the method of choice for the analysis of apoptosis in a variety of cell systems (Darzynkiewick et al., 1997; Lecoeur et al., 1997). Multiparameter analysis combines immunocytochemical detection of individual proteins with apoptotic markers and DNA analysis. It is a powerful approach to 
characterize cells committed to apoptosis and to define the components of the cell death machinery (Petit et al., 1995; Darzynkiewick et al., 1997; Lecoeur et al., 1997; Lecoeur et al., 1998; Bedner et al., 1999). Apoptotic cells exhibit an early loss of phospholipid asymmetry, leading to the exposure of PS residues on the outer layer of the plasma membrane (Fadok et al., 1992). Because annexin $\mathrm{V}$ binds to negatively charged phospholipids such as PS, FITCconjugated annexin $\mathrm{V}$ is classically used to identify apoptotic cells by flow cytometry (Vermes et al., 1995). During apoptosis, the cells become reactive to annexin $\mathrm{V}$ prior to the loss of both plasma membrane integrity and the ability to exclude PI. By staining the cells with a combination of annexin $\mathrm{V}$ and $\mathrm{PI}$, both apoptotic cells (annexin V1/PI-) and apoptotic necrotic cells (annexin V1/PI1) are detected. The annexin V1/PI- phenotype specifically identified apoptotic cells.

In vivo, using higher number of parasite inoculum, we tested in a short period of time the sensibility of $T$. cruzi to DFA. In 3 hours after infection, DFA was effective in reducing parasitaemia, demonstrating your direct action on the parasite. This result showed correlation with the reduction of parasitaemia of the prolonged treatment with DFA. Breidbach et al. (2002) evaluated the inhibition of the blood forms of Trypanosoma brucei by the DFA, and noted that the incubation of parasites with the chelator led to inhibition of DNA synthesis and oxygen consumption, indicating that the DFA can affect ribonucleotide reductase and alternative oxidase. In 6 hours, the DFA was not effective and this is probably due to the short half-life in plasma and rapid metabolism of DFA (Aouad et al., 2002). The results obtained with this method show a fairly good correlation with those obtained by prolonged treatment in this paper and schedules used to assess the action of drugs in experimental Chagas' disease (Filardi \& Brenner, 1984).

Through the mechanism the action of iron chelator, in this work was expected to decrease the levels of ferritin, serum iron and TIBC in groups receiving treatment with DFA, which in fact did not occur, showing that DFA effect on parasite was not dependent on host iron storages, this way, not decreased these levels.

The infection with parasites can alter the levels of host iron storages. Serum ferritin level is said to be useful for diagnosis of iron deficiency anemia, 
metabolism disorder and malignant tumor. Ferritin may also be an acute-phase protein and is often elevated in the course of disease. Recent studies have demonstrated new roles for ferritin, primarily related to immunity and autoimmunity (Recalcati et al., 2008). The concentration of serum iron is altered in the presence of infectious processes, can reduce a few hours after the development of an infection (Cook et al., 1992., Worwood, 1995). The TIBC they can increase before the reserves of iron are completely exhausted, reflecting depletion of reserves, however, is less sensitive than ferritin (Cook, 1992).

In the work carried out by Pedrosa et al. (1990), the reduction of serum iron in mice treated with DFA and infected by $Y, C L$ and $Y u Y u$ strains of the T. cruzi was not verified. Lalonde and Holbein (1984) demonstrated that no significant changes occurred in the levels of iron in serum of mice not-infected by T. cruzi and treated with DFA, while the infected and treated animals had presented sufficient iron supplies to keep a normal immune response. Arantes et al. 2007 observed that the serum iron levels of the infected/non-treated group were higher on the 21st day post-infection in comparison with control and infected/treated groups. Francisco et al. 2008 showed that serum iron concentrations were greater in group treated with DFA and the association DFA/Benznidazole compared to the infected group.

These results show that DFA failed to reduce the bioquimical iron levels of the host. In this work the DFA did not lead to a deficiency of iron in the host.

The DFA in this work does not alter the levels of hemoglobin, erythrocyte, hematocrit and platelets of mice infected or not by T. cruzi. Pedrosa et al. (1990) evaluated the iron deficiency in mice and correlated the effect of this deficiency with the evolution of Chagas' disease. The authors showed that the hypohemoglobinemia presented for the host was permanent in the group of mice fed with diet without iron, probably because it's the low supplies had not been enough to compensate the erythropoiesis that follows the anemia. In animals infected with $C L$ and $Y$ strain and treated with DFA the iron probably was recovered of the hemoglobin suggesting that this treatment did not intervene with the necessities required for erythropoiesis. Arantes et al. 2007 only observed differences in hemoglobin levels between infected and treated 
with DFA group compared with control treated group in $21 \mathrm{dpi}$, demonstrating no differences between infected treated and infected not treated group.

Since the discovery of Chagas disease 100 years ago, few studies have explored the causes of anemia associated with $T$. cruzi infection. Mice inoculated with different strains of the $T$. cruzi present intense thrombocytopenia (Cardoso et al., 1980) and neutropenia following by neutrophilia and eosinophilia (Repka et al, 1985). A similar hematological alteration have been also described in experimental African trypanosomiasis (lkede et al., 1977) and is a common characteristic of human immunodeficiency virus infection (Claster, 2002) and malaria (Weatherall et al., 2002 \& Paul et al., 2003). Marcondes et al. 2000 showed that experimental acute $T$. cruzi infection is associated with anemia, thrombocytopenia, leukopenia, and bone marrow hypoplasia and that these alterations can be prevented by nifurtimox (an anti-trypanosomal drug) treatment. However, the mechanisms responsible for these hematological alterations are not well understood. Recently, Stijlemans et al. 2008 demonstrated that during the acute and chronic phase of experimental Trypanosoma brucei infections that liver-associated erythrophagocytosis mediated by cytokine-activated macrophages is the most likely main initiating event of aggressive anemia during the acute phase of infection. Persistence of strong type I cytokine production during the chronic phase of infection leads to hyper-activated macrophages cells and a more progressive anemia.

In this paper, the animals infected and treated com DFA (T.cruzi + DFA) showed a higher percentage of lymphocytes in $7^{\text {th }}$ d.p.i may be more effective in controlling the infection by the response of your immune system, together with the direct action of the DFA on the parasite. The treatment with DFA had an impact on immune response in splenocytes of non-infected animals, increasing the population of $\mathrm{NK}, \mathrm{T}$ cells and $\mathrm{CD}^{+} \mathrm{T}$ cells cells throughout the treatment course. In infected animals, DFA had a direct impact on the cellular immune response, increasing the population of $T$ cells and $C D 8^{+} T$ cells and this may be related to decreased levels of parasitemia and increased survival rate.

Although little is known about the effect of DFA on the immune system of mice infected with $T$. cruzi, in previous study our research group observed in mice infected and treated with DFA an increase in weight of spleen, liver and lymph nodes in relation to their respective control in the $14^{\text {th }}$ d.p.i. In the $21^{\text {st }}$ 
d.p.i, there was an increase in relative weight of these organs only in the infected non-treated group. Possibly this early action of DFA allows the infected animals to mount more effective immune response, increasing their survival (unpublished data).

The development of a strong cellular immune response is a key factor in the control of $T$. cruzi infection. This occurs by the activation of a complex integrated immune response which involves cells from the innate and adaptive immune systems (Golgher and Gazzinelli, 2004).

Natural killer cells (NK) are essential for defense against infection induced by $T$. cruzi (Cardillo et al., 1996). Infection with T. cruzi results in augmentation of NK cell activity (Brodskyn et al., 1996). Also, NK cell depletion results in increased susceptibility to T. cruzi infection (Cardillo et al., 1996). Besides cytotoxic activity and cytokine secretion, NK cells can control B cell Ig secretion (Gray et al., 1995).

As part of experimental T. cruzi infection, some typical alterations concerning the immune system are observed, such as polyclonal $B$ and $T$ lymphocyte activation in secondary lymphoid organs, hypergammaglobulinemia, and immunosuppression towards homologous and heterologous antigens (Minoprio et al., 1989). Despite these abnormalities, specific immune responses can proceed to control parasitaemia, and the participation of $\mathrm{T}$ lymphocytes essential in this process as well as in the inflammatory response (Kierszenbaum, 1995).

The induction of protective immunity seems to be related to $C D 4^{+} T$ cells, as depletion of this subset leads to decreased inflammation and concomitant high levels of parasitaemia and tissue parasitism (Tarleton, 1995). In humans and mice, CD4+ lymphocytes produce substantial quantities of gamma interferon (IFN-y), which is important to both the humoral and cellular immune responses (Reed, 1998). In vivo parasite replication can be controlled by CD8+ T lymphocytes, important producer of IFN-y. In fact, mice lacking CD8+ T lymphocytes are more susceptible to infection, showing higher levels of parasitaemia and tissue parasitism yet displaying less inflammation in cardiac tissue (Tarleton et al., 1992). The B cells have important functions during the acute phase of an intracellular parasite infection, by regulating the pattern of the 
T-cell mediated immune response and/or the functional phenotypes of effector/memory CD8+ T cells (Cardillo et al., 2007).

In the present work, we observed that DFA was able to decrease parasite growth in in vitro fibroblast culture and mobility of trypomastigotes in culture, demonstrated the direct action on the parasite. In the animal model, the action of the DFA was independent of the effect on the homeostasis of iron metabolism. Infected animals treated with DFA showed lower parasitemia and mortality rates remain unchanged in spite of markers related to the dynamics of iron metabolism, such as levels of serum iron, ferritin, transferrin binding capacity and erythrocyte indices. These findings may indicate that the sensitivity of the parasite to the unavailability of micronutrients is larger than the host cell. However further analysis are still necessary to investigate the impact of DFA on the immunological status with involvement cytokine production following T. cruzi infection on were as it's relevant in the context of BZ chemotherapy. 


\section{Acknowledgment}

This work was supported by "Coordenação de Aperfeiçoamento de Pessoal de Nível Superior (CAPES), "Fundação de Amparo à Pesquisa do Estado de Minas Gerais" (FAPEMIG), "Centro de Pesquisa René Rachou, Fundação Osvaldo Cruz - FIOCRUZ (cpq/RR)" and by Federal University of Ouro Preto (UFOP), Brazil. 


\section{References}

Andrade, S.G., Freitas, L.A., Peyrol, S., Pimentel, A.R., Sadigursky, M., 1991a. Experimental chemotherapy of Trypanosoma cruzi infection: persistence of parasite antigens and positive serology in parasitologically cured mice. Bull World Health Organ 69,191-197.

Andrade, S.G., Stocker-Guerret, S., Pimentel, A.S., Grimaud, J.A., 1991b. Reversibility of cardiac fibrosis in mice chronically infected with Trypanosoma cruzi under specific chemotherapy. Mem Inst Oswaldo Cruz 86, 187-200.

Arantes, J.M., Pedrosa, M.L., Martins, H.R., Veloso, V.M., de Lana, M., Bahia, M.T., Tafuri, W.L., Carneiro, C.M., 2007. Trypanosoma cruzi: treatment with the iron chelator desferrioxamine reduces parasitaemia and mortality in experimentally infected mice. Experimental Parasitology 117, 43-50.

Ávila, H.A., Sigman, D.S., Cohen, L.M., Millikan, R. C., Simpson, L., 1991. Polymerase chain reaction amplification of Trypanosoma cruzi kinetoplast minicircle DNA isolated from whole blood lysates: diagnosis of chonic Chagas disease. Mol Biochem Parastiol 48, 211-222.

Blakley, B.R. e Hamilton, D.L., 1988. The effect of iron deficiency on the immune response in mice. Drug Nutrient Interactions 5, 249-255.

Bothwell, H., Charlton, R.W., Cook, J.D. e Finch, C.H., 1979. Iron metabolism in Man. Blackwell Oxford 284-306.

Bowern, N., Ramshaw, I.A., Clark, I.A., Doherty, P.C., 1984. Inhibition of autoimmune neuropathological process by treatment with an iron-chelating agent. J Exp Med 160, 1532- 1543.

Breidbach, T., Scory, S., Krauth-Siegel, R.L., Steverding, D. (2002). Growth inhibition of bloodstream forms of Trypanosoma brucei by iron chelator deferoxamine. Int J Parasitol 32, 473-479.

Brener, Z., 1962. Therapeutic activity and criterion of cure on mice experimentally infected with Trypanosoma cruzi. Rev Inst Med Trop São Paulo 4, 389-396.

Brittenham, G.M., 1988. Iron chelatings agents. In: Current Therapy in Hematology Oncology 3,149-153.

Brodskyn CI, Barral A, BulhoÄes MA, Souto T, Machado WC, Barral-Netto M., 1996. Cytotoxicity in patients with different clinical forms of Chagas' disease. Clin Exp Immunol 105: 450-455.

Buckner, F.S., Verlinde, C.L.M.J., La Flamme, A.C., Van Voorkhis, W.C., 1996. Efficient Technique for screening drugs for activity against Trypanosoma cruzi 
using parasites expressing $\beta$-Galactosidase. Antimicrob Agent Chemother 40: 2592- 2597.

Camargo, E.P. (1964). Growth and differentiation in Trypanosoma cruzi. I. Origin of metacyclic trypanosomes in liquid media. Rev Inst Med Trop Sao Paulo 12, 93-100.

Cardillo F, Voltarelli JC, Reed SG, Silva JS., 1996. Regulation of Trypanosoma cruzi infection in mice by gamma interferon and interleukin 10: role of NK cells. Infect Immun 64: 128-134.

Cardillo et al., 2007. B cells modulate $T$ cells so as to favour $T$ helper type 1 and CD8+ T-cell responses in the acute phase of Trypanosoma cruzi infection. Immunology, 122, 584- 595.

Cardoso, J.E. e Brener, Z., 1980. Hematological changes in mice experimentally infected with Trypanosoma cruzi. Mem Inst Oswaldo Cruz 75, 97-104.

Carotenuto, P., Pontesilli, O., Cambier, J.C., Hayward, A.R., 1986. Desferoxamine blocks IL- 2 receptor expression on human T lymphocytes. J Immunol 136, 2342-2347.

Cinatl, J. Jr., Cinatl, J., Weber, B., Rabenau, H., Gumbel, H.O. Chenot, J.F., Scholz, M., Encke, A., Doerr, H.W., 1995. In vitro inhibition of human cytomegalovírus replication in human foreskin fibroblasts and endotelial cells by ascorbic acid 2-phosphate. Antiviral Res 27, 405-418.

Claster, S., 2002. Biology of anemia, differential diagnosis, and treatment options in human immunodeficiency virus infection. J Infect Dis 85: 105-109.

Cook, J.D., Baynes, R.D., Skikne,B.S., 1992. Iron deficiency and the measurement of iron status. Nutr Res Rev 5: 189-202.

Crichton, R.R. and Ward, R.J., 1992. Structure and molecular biology of iron binding-proteins and the regulation of free iron pools. In: Lauffer RB, editor. Iron and human diseases. Boca Raton CRC Press Inc 10, 23-75.

Dallman, P.R., 1986. Biochemical basis for the manifestations of iron deficiency. Ann Rev Nutr 6, 13-40.

Dhur, A., Galan, P. e Hercberg, S., 1989. Iron status, immune capacity and resistance to infections. Comp Biochem Physiol 94, 11-19.

Donfrancesco, A., Deb, G., De Sio, L., Cozza, R., Castellano, A., 1996. Role of desferrioxamine in tumor therapy. Acta Haematol 95, 66-69.

Esievo, K.A., Saror, D.I., llemobade, A.A. e Hallaway, M.H., 1982. Variation in erytrocyte and free sialic acid serum concentrations during experimental Trypanosoma vivax infection in cattle. Res Vet Sci 32, 1-15. 
Fielding, J., 1965. Differential ferrioxamine test for measuring chelatable body iron. J Clin Pathol 18: 88-97.

Filardi, L.S. e Brener, Z., 1987. Susceptibility and natural resistance of Trypanosoma cruzi strains to drugs used clinically in Chagas disease. Transactions of the Royal Society of Tropical Medicine and Hygiene 81, 755759.

Francisco, A.,Vieira, P.M.A., Arantes, J.M., Pedrosa, M.L., Martins, H.R., Silva, M., Veloso, V.M., de Lana, M., Bahia, M.T., Tafuri, W.L., Carneiro, C.M., 2008. Trypanosoma cruzi: Effect of benznidazole therapy combined with the iron chelator desferrioxamine in infected mice. Experimental Parasitology 120:314319.

Galan, P., Davila, M., Mekki, N. e Hereberg, S., 1988. Iron deficiency, inflammatory processes and humoral immunity in children. Int $\mathrm{J}$ Vit Nutr Res 58, 225-230.

Galvão, L., Nunes, R., Cançado, J.R., Brener, Z., Krettli, A. (1993). Lytic antibodies titer as a means of assessing cure after treatment of Chagas' disease: a 10 year follow-up study. Trans $R$ Soc Trop Med Hyg 87, 220- 223.

Golgher, D., Gazzinelli, R., 2004. Innate and acquired immunity in the pathogenesis of Chagas disease. Autoimmunity 37: 399-409.

Gomes, M.L., Macedo, A.M., Vago, A.R., Pena, S.D., Galvão, L.M., Chiari, E., 1998. Trypanosoma cruzi: optimization of polymerase chain reaction for detection in human blood. Exp Parasitol 88, 28- 33.

Gordeuk, K., Thuma, P., Brittenham, G., McLaren, C., Parry, D., Backenstose, A., Biemba, G., Msiska, R., Holmes, L., McKinley, E., Vargas, L., Gilkeson, R., Polera, A.A., 1992. Effect os iron chelation therapy on recovery from deep coma in children with cerebral malaria. The New England Journal of Medicine 327, 1473-1477.

Gray JD, Horwitz DA.,1995. Activated human NK cells can stimulate resting B cells to secrete immunoglobulin. J Immunol 154: 5656-5664.

Hann, H.W.L., Stahlhut, M.W., Rubin, R., Maddrey, W.C., 1992. Antitumor effect of deferoxamine on human hepatocellular carcinoma growing in athymic nude mice. Cancer 70, 2051-2056.

Harvey, P.W.J., Bell, R.G. e Nesheim, M.C., 1985. Iron deficiency protects inbred mice against infection with Plasmodium chabaudi. Infect Immunit 50, 932934.

Hershko, C. and Peto, T.E.A., 1988. Deferroxamine inhibition of malaria is independent os host iron status. J Exp Med 168, 375-387. 
Igbokwe, I.O. e Anosa, V.O., 1989. Response to anaemia in experimental Trypanosoma vivax infection of sheep. J Comp Path 100, 111-118.

Ikede, B.O., Lule, M., Terry, R.J., 1977. Anemia in trypanosomiasis: mechanisms of erythrocyte destruction in mice infected with Trypanosoma congolense or T.brucei. Acta Trop 34: 53-60.

Keberle, H. (1964). The biochemistry of desferrioxamine and its relation to iron metabolism. Ann NY Acad Sci 119: 759-768.

Kent, S., Weinberg, E.D e Stuart-MacAdam, P., 1990. Dietary and prophylactic iron supplements: helpful and harmful. Human Nature 1, 55-81.

Kierszenbaum, F. 1995. What are T cell subpopulations really doing in Chagas' disease? Parasitol. Today 11: 6-7.

Kontogiorghes, G.J., 1995. Comparative efficacy and toxicity of desferrioxamine, deferiprone and other iron and aluminum chelating drugs. Toxicol Lett 80: 1-18.

Lalonde, R.G. e Holbein, B.E., 1984. Role of iron in Trypanosoma cruzi infection of mice. J Clin Invest 23, 470-476.

Letendre, E.D., 1985. The importance of iron in the pathogenesis of infection and neoplasia. Trends Biochem Sci 12, 166-168.

Lima, M.F. e Villalta, F., 1989. Trypanosoma cruzi trypomastigote clones differentially express a parasite adhesion molecule. Mol Biochem Parasitol 33, 159-170.

Loo, V.G. e Lalonde, R.G., 1984. Role of iron in intracellular growth of Trypanosoma cruzi. Infect Immun 45, 726-730.

Mabeza, G.F., Biemba, G., Gordeuk, V.R., 1996. Clinical studies of iron chelators in malaria. Acta Haematologica 95, 78-86.

Mahmoud, M.S., 1999. Effect of deferoxamine alone and combined with pyrimethamine on acute toxoplasmosis in mice. J Egypt Soc Parasitol 29, 791803.

Marcondes, M.C.G., Borelli, P., Yoshida, N., Russo, M., 2000. Acute Trypanosoma cruzi infection is associated with anemia, thrombocytopenia, leukopenia, and bone marrow hypoplasia: reversal by nifurtimox treatment. Microbes and infection 2, 347-352.

Martelius, T., Scholz, M., Krogerus, L., Hockerstedt, K., Loginov, R., Bruggeman, C., Cinatl JR, J., Doerr, H.W., Lautenschlager, I., 1999. Antiviral and immunomodulatory effects of desferrioxamine in cytomegalovirus-infected rat liver allografts with rejection. Transplantation 68, 1753-1761. 
Minotti, G., Aust, S.D.,1987. The role of iron in the initiation of lipid peroxidation. Chem Phys Lipids 44: 191-208.

Minoprio, P., Itohara, S., Heusser, C., Tonegawa, S., Coutinho, A ., 1989. Immunobiology of murine Trypanosoma cruzi infection: the predominance of parasite- nonspecific responses and the activation of TCRI T cells. Immunol. Rev. 112: 183-207.

Miyamoto, C.T., Gomes, M.L., Marangon, A.V., Araujo, S.M., Bahia, M.T. Lana, M., Toledo, M.J. (2006). Trypanosoma cruzi: sensitivity of the polymerase chain reaction for detecting the parasite in the blood of mice infected with different clonal genotypes. Exp Parasitol 112,198-201.

Oliveira, R.B., Vaz, A.B.M., Alves, R;O., Liarte, D.B., Donnici, C.L., Romanha, A.J., Zani, C.L., 2006. Arylfurans as potential Trypanosoma cruzi trypanothione reductase inhibitors. Mem Inst Oswaldo Cruz 101: 169-173.

Paul, R.E., Brey, P.T., 2003. Malaria Parasites and red blood cells: from anaemia to transmission. Mol. Cells 15: 139-149.

Pedrosa, M.L., Nicoli, J.R., Silva Marcelo, E., Silva Márcio, E., Silva, M.E.C., Vieira, L.Q., Bambirra, E.A. e Vieira, E.C., 1993. The effect of iron nutritional status on Trypanosoma cruzi infection in germfree and conventional mice. Comp Biochem Physiol 106 , 813-821.

Pedrosa, M.L., Silva Marcelo, E., Silva Márcio, E., Silva, M.E.C., Nicoli, J.R. e Vieira, E.C., 1990. The effect of iron deficiency and iron overload on the evolution of Chagas' disease produced by three strains of Trypanosoma cruzi in CFW mice. Comp Biochem Physiol 97, 235-243.

Rachidi, S., Coudray, C., Baret, P., Gelon, G., Pierre, J.L., Favier, A., 1994. Inhibition of lipid peroxidation by a new family of iron chelators. Comparison with desferrioxamine. Biol Trace Elem Res 41: 77-87.

Recalcati, S., Invernizzi, P., Arosio, P., Cairo, G., 2008. New functions for an iron storage protein: The role of ferritin in immunity and autoimmunity. Journal of Autoimmunity 30: 84-89.

Reed, S.G.,1998. Immunology of Trypanosoma cruzi infections. Chem. Immunolog. 70: 124-143.

Repka, D., Rangel, H.A., Atta, A.M., Gavino, V.A., Piedrabuena, A.E., 1985. Experimental Chagasás diseases in mice infected with one $L^{50}$ of parasite. Rev. Bras. Biol 45: 309-316.

Wincker P., Britto C., Pereira J.B., Cardoso M.A., Oelemann, W., Morel, C.M. 1994. Use of a simplified polymerase chain reaction procedure to detect Trypanosoma cruzi in blood samples from chronic chagasic patients in a rural endemic area. Am J Trop Med Hyg 51,771-777. 
Richardson, D.R., 1997. Iron chelators as effective anti-proliferative agents. Can J Physiol Pharmacol 75, 1164-1180.

Richardson, RD., 2004. Novel chelators for central nervous system disorders that involve alterations in the metabolism of iron and other metal ions. Ann NY Acad Sci 1012: 326-341.

Rouser, G.; Nelson, G.J.; Fleicher, S., 1968. Lipid composition of animal cell membranes, organelles and organs. In: Chapman D. Biological membranes: physical fact and function. New York: Academic Press 5-69.

Ruiz, R.C., Fernandes, M. e Irulegui, I., 1989. Observation of marked thrombcytopenia during the course of acute experimental Chagas' disease. Mem Inst Oswaldo Cruz 84, 26.

Santos, F.R., Pena, S.D.J., Epplen, J.T., 1993. Genetic and population study of a Y-linked tetranucleotide repeat DNA polymorphism with a simple non-isotopic technique. Hum Genet 90, 655-656.

Shadid, M., Buonocore, G., Groenendaal, F., Moison, R., Ferrali, M., Berger, H.M., Van Bel, F., 1998. Effect of deferoxamine and allopurinol on non-proteinbound iron concentrations in plasma and cortical brain tissue of newborn lambs following hypoxia-ischemia. Neurosci Lett 248, 5-8.

Silva L.H.P. e Nussenzweig V. (1953). Sobre uma cepa de Trypanosoma cruzi altamente virulenta para o camundongo branco. Folia Clin Biol 20, 191-203.

Spellberg, B., Edwards,J Jr., Ibrahim, A.., 2005. Novel perspectives on mucormycosis: pathophysiology, presentation, and management. Clin Microbiol Rev 18: 556-569.

Stijlemans, B., Vankrunkelsven, A., Brys, L., Magez, S., De Baetselier., P., 2008. Role of iron homeostasis in trypanosomiasis-associated anemia. Immunobiology 213: 823-835.

Tang, L.X.; Yang, J.L.; Shen, X., 1997. Effects of additional iron-chelators on $\mathrm{Fe}(2+)$-initiated lipid peroxidation: evidence to support the $\mathrm{Fe}^{2+} \mathrm{Fe}^{3+}$ complex as the initiator. J Inorg Biochem 68: 265-272.

Tanjii, K., Imaizumi, T., Matsumiya, T., Itaya, H., Fujimoto, K., Cui, X.F., Toki, T., Ito, E., Yoshida, H., Wakabayashi, K., Satoh K., 2001. Desferrioxamine, an iron chelator, upregulates cyclooxygenase-2 expression and prostaglandin production in a human macrophage cell line. Bioch et Biophy Acta 1530, 227235.

Tarleton, R.L.,1995. The role of T cells in Trypanosoma cruzi Infection. Parasitol. Today 1:7-9.

Traore, O., Carnevale, P., Kaptue-Noche, L., Bede, J., Desfontaine, M., Elion, J., Labie, D., Nagel, R.L., 1991. Preliminary reports in the use of desferrioxamine in 
the treatment of Plasmodium falciparum malaria. American Journal of Hematology 37, 206-208.

Voller, A., Bidwell, D.E., Bartlett, A., 1976. Enzyme immunoassays in diagnostic medicine. Theory and pratice. Bull WHO 53, 55-65.

Wang, F., Elliot, R.L., Head, J.F., 1999. Inhibitory effect of deferoxamine mesylate and low iron diet on the $13762 \mathrm{NF}$ rat mammary adenocarcinoma. Anticancer Res 19, 445-450.

Weatherall, D.J., Miller, L.H., Baruch, D.I., Marsh, K., Doumbo, O.K., CasalsPascual, C., Roberts, D.J., 2002. Malaria and red cell. Hematology (Am.Soc. Hematol. Educ. Program) 35-57.

Weinberg, E.D., 1984. Iron withholding: a defense against infection and neoplasia. Physiol Rev 64, 65-102.

Weinberg, G. A., 1994. Iron chelators as therapeutic agents against Pneumocystis carinii. Antimicrobial Agents and Chemotherapy 38, 997-1003.

Weiss, G., Fuchs, D., Hausen, A., Reibnegger, G., Werner, E.R., WernerFelmayer, G., Wachter, H., 1992. Iron modulates interferon gamma effects in the human myelomonocytic cell line THP-1. Exp Hematol 20,605-610.

Weiss, G., Thuma, P.E., Mabeza, G., Werner, E.R., Herold, M., Gordeuk, V.R., 1997. Modulatory potential of iron chelation therapy on nitric oxide formation in cerebral malaria. J Infection Dis 175, 226-230.

White, K., Munro, H.N., 1988. Induction of ferritin subunit synthesis by iron is regulated at both the transcriptional and translational levels. J Biol Chem 263: 8938-8942.

Wincker P., Britto C., Pereira J.B., Cardoso M.A., Oelemann, W., Morel, C.M. 1994. Use of a simplified polymerase chain reaction procedure to detect Trypanosoma cruzi in blood samples from chronic chagasic patients in a rural endemic area. Am J Trop Med Hyg 51,771-777.

Wolfe, L., Leitzel, K., Witkoski, E., Bartholomew, M., Lipton, A., 1988. Desferrioxamine prolongs survival of mice with LI210 lymphocytic leukaemia. Proc Am Assoc Cancer Res 29, 2053.

Worwood, M., 1995. Iron deficiency anaemia, In: Dacie SJV, Lewis SM, editors. Practical Haematology 437-444.

Yu, Y., Wong, J., Lovejoy, D.B., Kalinowski, D.S., Richardson, D.R., 2006. Chelators at the cancer coalface: desferrioxamine to Triapine and beyond. Clin Cancer Res 12: 6876- 6883.

Zanninell, G., Glickstein, H., Breuer, W., Brissol, P., Hider, R.C., Cabantchick, Z.I., 1997. Chelation and mobilization of cellular iron by different classes of chelators. Mol Pharmacol 51: 842-852. 


\section{Legend:}

Figure 1- a) Swiss mice $(n=20)$ were inoculated with 500 T. cruzi $Y$ strain trypomastigotes and received no treatment (control) or DFA for up to 28 days from 14 days before infection. Parasitaemia and mortality were obtained at 14 days after infection. b) $T$. cruzi (Tulahuen strain) expressing Escherichia coli beta-galactosidase gene was cultured for 4 days in L929 fibroblasts in the presence of different concentrations of DFA. Trypanocidal activity was calculated by b-galactosidase activity. The results are expressed as percentage growth inhibition. BZ was used as positive control. c) Y strain trypomastigotes were cultured in L929 cells in the presence of different concentrations of DFA and had their motility evaluated after 1, 3, 6, 9 and 12 hours. BZ and gentian violet were used as control.

Figure 2- Trypomastigotes cells were cultured in L929 cells in the presence or not of DFA. BZ and gentian violet were used as control. Suspension of $1 \times 106$ parasites was double stained with FITC-conjugated annexin V and PI. Parasites showing no staining by either annexin or PI were considered alive (white). Parasites stained with the annexin alone were considered in early apoptotic process (black). Parasites stained by both $\mathrm{PI}$ and annexin were considered in late apoptotic process (light gray). Parasites stained with $\mathrm{PI}$ alone were considered dead (dark gray).

Figure 3- Swiss mice $(n=20)$ were inoculated with 50.000 T.cruzi $Y$ strain trypomastigotes and received no treatment (control), DFA $25 \mathrm{mg} / \mathrm{kg}$, BZ 500 $\mathrm{mg} / \mathrm{kg}$ or BZ $500 \mathrm{mg} / \mathrm{kg}$ + DFA $25 \mathrm{mg} / \mathrm{kg}$. Parasitemia was estimated before, 3 and 6 hours after treatment.

Figure 4- Swiss mice $(n=30)$ were (T. cruzI) or not (control) inoculated with 500 T. cruzi $Y$ strain trypomastigotes and received no treatment or desferrioxamine (DFA) for up to 35 days from 14 days before infection. Levels of ferritin, serum iron and capacity iron binding were measured before, 7, 14 and 21 days after infection. Values shows are means \pm SEM. 
Figure 5- Swiss mice $(n=30)$ were or not inoculated with 500 T. cruzi $Y$ strain trypomastigotes and received no treatment or desferrioxamine (DFA) for up to 35 days from 14 days before infection. Splenocytes were cultured for 12 hours in culture medium and stained for NK cells (CD49), T cells (CD4+CD8) and B cells (CD19).

Figure 6- Swiss mice $(n=30)$ were or not inoculated with 500 T. cruzi $Y$ strain trypomastigotes and received no treatment or desferrioxamine (DFA) for up to 35 days from 14 days before infection. Splenocytes were cultured for 12 hours in culture medium and stained with anti-CD4 and anti-CD8. 